\title{
Job satisfaction and its associated factors among optometrists in Ghana: a cross-sectional study
}

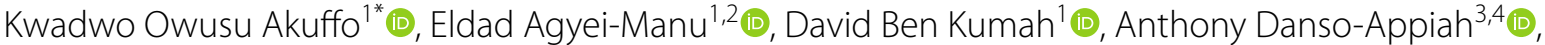

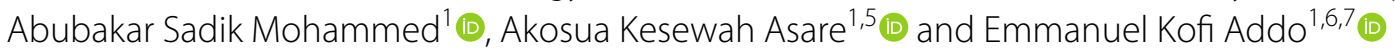

\begin{abstract}
Background: Job satisfaction describes an employee's motivation and/or feeling of satisfaction towards his/her work. Globally, healthcare professionals' turnover and retention play a critical role in the delivery of essential health services. In Ghana, however, little has been done to ascertain job satisfaction levels among human resources for eyehealth. The objective of this study therefore was to assess job satisfaction and its associated factors among optometrists in Ghana.
\end{abstract}

Methods: A cross-sectional survey was conducted among 304 registered and licensed optometrists of the Ghana Optometric Association between September 2018 and June 2019. A validated, well-structured questionnaire was used to elicit information on socio-demographic characteristics of participants and measures on job satisfaction. Scores from a five-point Likert scale was employed to examine job satisfaction and its associated factors. Linear regression analyses were used to evaluate the association between overall job satisfaction and its associated factors using Rasch logit scores.

Results: A total of 214 optometrists gave valid responses to the questionnaires used for the final analysis. The mean $( \pm S D)$ score of the overall perception of job satisfaction among optometrists was 3.36 ( \pm 1.00 ), with $74.3 \%$ of them being satisfied with their jobs. After statistical adjustment, Good work-life balance (Unstandardized co-efficient $(\beta)=0.288, p=0.001)$, Salary $(\beta=0.222, p<0.0005)$, Supervision $(\beta=0.117, p=0.044)$, and Continuing Education Opportunities $(\beta=0.138, p=0.017$ ) were all significantly associated with higher levels of overall job satisfaction.

Conclusions: Most optometrists were satisfied with their jobs. Effective strategic planning and management of human resources for eye-health in Ghana are essential in the development of quality eye-health systems and the provision of high-quality eyecare services.

Keywords: Determinants, Factors, Healthcare professionals, Ghana, Job, Job satisfaction, Optometrist, Satisfied

\section{Background}

Over the years, healthcare professionals' retention and satisfaction have played a critical role in the delivery of essential healthcare services in any organization

\footnotetext{
*Correspondence: akuffokwadwoowusu@knust.edu.gh; koakuffo@gmail.com ${ }^{1}$ Department of Optometry and Visual Science, College of Science, Kwame Nkrumah University of Science and Technology, Kumasi, Ghana Full list of author information is available at the end of the article
}

worldwide. Job satisfaction, a multidimensional concept, highlights the level of an employee's contentment and motivational drive towards achieving organizational goals $[1,2]$. A systematic review by Willis-Shattuck, Bidwell [3] showed that healthcare professionals' retention and turnover in developing countries such as Ghana, has become a major threat to achieving access to quality health care, as enshrined in the Sustainable Development original author(s) and the source, provide a link to the Creative Commons licence, and indicate if changes were made. The images or other third party material in this article are included in the article's Creative Commons licence, unless indicated otherwise in a credit line to the material. If material is not included in the article's Creative Commons licence and your intended use is not permitted by statutory regulation or exceeds the permitted use, you will need to obtain permission directly from the copyright holder. To view a copy of this licence, visit http://creativecommons.org/licenses/by/4.0/. The Creative Commons Public Domain Dedication waiver (http://creativeco mmons.org/publicdomain/zero/1.0/) applies to the data made available in this article, unless otherwise stated in a credit line to the data. 
Goal 3 (good health and well-being). The diverse factors which are considered a sine qua non for job satisfaction among different healthcare professionals [4], if adequately satisfied, provide the right environment for utmost productivity. In Ghana, a survey by Bonenberger et al. [5] on turnover intentions by healthcare professionals such as doctors, nurses, pharmacists and allied healthcare professionals (e.g. optometrists) showed that $69 \%$ of them had intentions of exiting their health facilities due to low levels of job satisfaction.

The theories that explain job satisfaction provide the basis to identify the various factors which influence job satisfaction and suggest ways of improving employee's job satisfaction. These theories include the Herzberg's motivator-hygiene theory [6], the Maslow's needs hierarchy theory [7], the dispositional approach [8], and the Job Characteristics Model [9]. Although little empirical evidence has been documented for the Maslow's needs hierarchy and the Herzberg's motivator-hygiene theories [10], the Job Characteristics Model and dispositional approach continue to accumulate empirical evidence to suggest that job satisfaction among employees is usually affected by psychological and personality factors [11]. Nevertheless, motivational factors tend to influence the immediate job environment and subsequently impact how employees are satisfied with their jobs.

Diverse studies have shown that there are various determinants for job satisfaction among healthcare professionals such as optometrists, physicians, nurses, etc. [12-14]. These factors, which include salary, job security, supervision, supportive working environment, etc. $[3,4$, 15], ultimately considerably impact the quality of health delivery services and may lead to low productivity [16]. In Ghana, it has been shown that poor working conditions such as low financial incentives, poor working environment, unavailability of resources, and lack of opportunities for career development lead to job dissatisfaction among healthcare professionals, including optometrists, and consequently lead to increased turnover and low patient care [17].

There have been concerns about optometrists' job satisfaction due to their crucial role in the delivery of quality eyecare services to patients [18-20] and the potential for optometrists' turnover [14]. As primary eyecare providers, optometrists provide essential vision-related services such as refractive correction $[21,22]$, detection and management of eye diseases [23], as well as specialized eyecare services such as low vision rehabilitation [24], vision therapy [25], and contact lens fitting [26]. These essential eye health services have contributed significantly to achieving VISION 2020 (eliminating avoidable visual impairment and blindness), especially in sub-Saharan Africa $[27,28]$. In Ghana, however, optometrists play a critical role in the delivery of comprehensive refractive error services. As opposed to other eyecare cadres such as ophthalmologists and ophthalmic nurses, optometrists primarily undergo comprehensive training in visual function and optical technology services, which is aimed at correcting people with refractive defects in their vision/ visual system [29]. Refractive errors have been shown to increase the burden of avoidable blindness and considerably impact the quality of life of affected individuals. Notably, a systematic review and meta-analysis by Hashemi et al. [30] provided evidence that the prevalence of myopia, hyperopia, and astigmatism among adults in Africa was $11.4 \%, 38.6 \%$, and $16.2 \%$, respectively, as opposed to $14.2 \%, 3.0 \%$, and $6.2 \%$, respectively in children. The central role of optometrists in the provision of quality refractive error services in Ghana is inevitably needed in reducing the burden of avoidable visual impairment and blindness in the country [31].

In spite of this significant role by optometrists in Ghana's eyecare industry, little or no study has been conducted to assess their job satisfaction level and provide evidence base for policy direction in addressing the growing needs of optometrists in the country. The World Health Organization's (WHO) "Global Strategy on Human Resources for Health: Workforce 2030" sets out the policy agenda to ensure a workforce that is fit for purpose to attain the targets of the Sustainable Development Goals (SDGs). This agenda considers the emerging evidence that addressing the job challenges faced by health workers and investments in the health workforce, including optometrists, could further generate socio-economic development and sustainable economic growth. Low morale among the optometric workforce in Ghana may undermine the quality of specialized eyecare services provided to the populace. This study therefore sought to assess the level of job satisfaction among optometrists in Ghana and its associated determinants. This important novel study would provide primary data (for the first time) to assist the development of human resource policies regarding optometric practice and healthcare administration in Ghana.

\section{Methods}

\section{Study aim, design, setting, and population}

This cross-sectional survey, conducted between September 2018 and June 2019, assessed the factors affecting job satisfaction among optometrists in Ghana. Ghana is a lower-middle income country (a country with a total economic value between $\$ 1006$ and \$3955) [32] in the subSaharan African region (West Africa), and shares borders with Cote D'Ivoire (in the west), Burkina Faso (in the north), Togo (in the east), and the Gulf of Guinea (in the south). The country has a population of about 30 million 
people with about $2.15 \%$ growth rate, and a total land area of about 238,533 $\mathrm{km}^{2}$ [32]. As at the commencement of this study, Ghana was broadly divided into 10 regions (currently 16 regions), namely the Greater Accra, Central, Western, Eastern, Brong-Ahafo, Ashanti, Volta, Northern, Upper East, and Upper West regions. The study population encompassed all registered optometrists of the Ghana Optometric Association (GOA), across all regions of the country. GOA is the professional body responsible for the advancement of optometry in Ghana and harmonizes the activities of optometrists with the Allied Health Professions Council of Ghana (AHPC).

\section{Study participants}

An official letter was sent to the GOA requesting permission to conduct the study. The letter also stated the purpose of the study. Upon review and further correspondence with the GOA, formal communication was sent by the leadership of the GOA to all its members across the country, informing them about the study and encouraging members to participate. GOA subsequently provided a professional registry of all its members. The professional registry of GOA in 2018, as at the commencement of the study, had 406 registered optometrists. However, on further review of the GOA's database, the study investigators excluded optometrists who had no/ wrong contact information/details (email addresses and/ or telephone numbers) or were currently working outside Ghana. Subsequently, a total of 304 optometrists were eligible for the study and were contacted via email or visit to participate in the study. However, a total of 214 optometrists responded to the study by completing study questionnaires; representing a participation rate of $70.4 \%$.

\section{Data collection}

A validated, well-structured questionnaire adapted from Paudel et al. [33] with both open- and closed-ended questions was administered to all the participants. The questionnaires were administered either through a faceto-face interview or via email (google form) [34], after explaining instructions and essential terms to the participants. The details of both softcopy and hardcopy questionnaires were the same. The questionnaire was composed of two sections. The first section (Part A), comprising 21 items, elicited information on the sociodemographic characteristics of participants such as age, sex, marital status, number of children (if any), highest educational level, location of workplace, practice setting, working hours per week, work experience, goodwork-life balance, first job appointment, and duration for a first job appointment. The second section (Part B), comprising 15 items, elicited information on the 14 factors responsible for participants' level of satisfaction with their current job, as well as their overall perception on the level of job satisfaction (item 15 in the second section). The factors assessed in this section included salary; non-financial incentives (e.g. vacation, sick leave, etc.); job security; workplace equipment and facilities; supervision; encouragement, reward and positive feedback from institution; recognition by co-workers, level of job responsibility; task variety; workload; level of control over job; support from co-workers; continuing education opportunities; and opportunities for career advancement. A five-point Likert scale was used to assess all 15 items in the second section; 1-very dissatisfied, 2-dissatisfied, 3-neither satisfied nor dissatisfied, 4-satisfied, and 5very satisfied. Each face-to-face interview generally lasted for about $20 \mathrm{~min}$ whereas the filling of online questionnaires lasted for about $10 \mathrm{~min}$.

\section{Ethical approval}

The study adhered to the Declaration of Helsinki and was approved by the Committee on Human Research Publication and Ethics of the Kwame Nkrumah University of Science and Technology (KNUST), College of Health Sciences (CHRPE/AP/034/19). Permission was obtained from the GOA. Written informed consent was obtained from all participants after explaining the objectives, nature, method and importance of the study to them.

\section{Statistical analysis}

The data obtained were analysed using Statistical Product and Service Solution (IBM Corporation IBM $^{\circledR}$ SPSS $^{\circledR}$ Statistics for Windows, Version 25.0 Armonk, NY) compatible with Windows 10. Frequencies and percentages of demographic variables, as well as the determinants of job satisfaction were analyzed using descriptive statistics.

For this study's analyses, the overall perception of each participant's job satisfaction was calculated by finding an average score of the 14 items (factors) for job satisfaction, and subsequently classified job satisfaction among participants into two groups based on the average scores obtained: Satisfied (having an average score greater than 3) and Not satisfied (having an average score less than or equal to 3). Also, the average of the scores for selfreported overall job satisfaction by all participants (item 15 in the second section of questionnaire) was calculated.

Rasch logit scores were employed in bivariate simple linear and multivariate linear regression models. Only variables found to be significantly associated with overall level of job satisfaction $(p<0.05)$ in bivariate models were selected for inclusion in multivariate linear regression analyses. 


\section{Results}

A total of 121 (56.5\%) completed online questionnaires and 93 (43.5\%) completed printed questionnaires were obtained at the end of the study.

\section{Socio-demographic characteristics of participants}

The mean ( \pm standard deviation $[\mathrm{SD}])$ age of all participants was $33.1 \pm 6.0$ years (with age range $24-60$ years). Majority of the participants were males (69.6\%), married (57.0\%) and aged 31-45 years (60.7\%). Most optometrists worked in the urban setting $(81.3 \%)$ and the private practice setting (44.9\%). A greater proportion of participants $(81.8 \%)$ had obtained a Doctor of Optometry (OD) degree as their highest level of education, with most of them having about 6-10 years of work experience (50.9\%). Table 1 shows the socio-demographic profile of the participants.

\section{Distribution/nature of optometric workforce and practice}

Most optometrists were working in the Greater Accra (39.3\%) and Ashanti (27.6\%) regions of Ghana (southern sector of the country), whereas a limited number of them worked in the Upper West (0.5\%) and Upper East (0.9\%) regions of Ghana (northern sector of the country). A large proportion of optometrists were working in Municipal/District Hospitals (32.2\%), while a few optometrists worked in Regional (6.1\%) and Tertiary (7.0\%) hospitals. Less than half of the total participants $(41.1 \%)$ were currently working in their first job appointment, and 70.1\% of all participants had obtained their first job appointment within three months after optometry study. With reference to clinical practice, the following were recorded for various ophthalmic procedures being undertaken by participants at their workplaces: refraction (98.6\%); clinical examination, management and referral (95.8\%); optical dispensing (66.4\%); contact lens fitting (29.4\%); low vision care $(23.8 \%)$; community outreach $(75.2 \%)$, research activities (22.9\%), and diagnostic unit (37.4\%) (see Table 1).

\section{Motivation for choosing optometry practice}

Concerning the reasons why participants chose to offer optometry at the tertiary level, most optometrists (45.9\%) reported that they were very interested in health and eyecare. The other reasons given were as follows; $19.0 \%$ reported that they wanted to earn good income, 13.2\% reported that they wanted to provide voluntary assistance to the needy and NGOs, $12.9 \%$ reported that they believed they could become eye doctors, 3.0\% reported that optometry was their only opportunity to study after school, $2.2 \%$ reported that they were influenced by their
Table 1 Demographic profile of participants

\begin{tabular}{|c|c|}
\hline Characteristic & n (\%) \\
\hline \multicolumn{2}{|l|}{ Age (years) } \\
\hline$\leq 30$ & $74(34.6)$ \\
\hline $31-45$ & $130(60.7)$ \\
\hline $46-60$ & $10(4.7)$ \\
\hline \multicolumn{2}{|l|}{ Sex } \\
\hline Male & $149(69.6)$ \\
\hline Female & $65(30.4)$ \\
\hline \multicolumn{2}{|l|}{ Highest Educational level } \\
\hline Post-graduate Diploma (optometry) & $2(0.9)$ \\
\hline Doctor of Optometry & $175(81.8)$ \\
\hline Fellowship & $2(0.9)$ \\
\hline Masters & $28(13.1)$ \\
\hline Doctor of Philosophy & $7(3.3)$ \\
\hline \multicolumn{2}{|l|}{ Marital Status } \\
\hline Single & $85(39.7)$ \\
\hline Married & $122(57.0)$ \\
\hline Divorced & $7(3.3)$ \\
\hline \multicolumn{2}{|l|}{ Number of children } \\
\hline 0 & $106(49.5)$ \\
\hline$\geq 1$ & $108(50.5)$ \\
\hline \multicolumn{2}{|l|}{ Region of workplace } \\
\hline Greater Accra & $84(39.3)$ \\
\hline Western & $10(4.7)$ \\
\hline Central & $21(9.8)$ \\
\hline Eastern & $14(6.5)$ \\
\hline Ashanti & $59(27.6)$ \\
\hline Brong Ahafo & $10(4.7)$ \\
\hline Volta & $8(3.7)$ \\
\hline Northern & $5(2.3)$ \\
\hline Upper East & $2(0.9)$ \\
\hline Upper West & $1(0.5)$ \\
\hline \multicolumn{2}{|l|}{ Location of workplace } \\
\hline Urban & $174(81.3)$ \\
\hline Rural & $40(18.7)$ \\
\hline \multicolumn{2}{|l|}{ Practice Setting } \\
\hline Government & $62(29.0)$ \\
\hline CHAG/NGO & $42(19.6)$ \\
\hline Private & $96(44.9)$ \\
\hline Academic & $11(5.1)$ \\
\hline Others & $3(1.4)$ \\
\hline \multicolumn{2}{|l|}{ Working hours per week } \\
\hline $0-40$ & $151(70.6)$ \\
\hline$\geq 41$ & $63(29.4)$ \\
\hline \multicolumn{2}{|l|}{ Work experience (years) } \\
\hline $0-5$ & $82(38.3)$ \\
\hline $6-10$ & $109(50.9)$ \\
\hline$\geq 11$ & $23(10.7)$ \\
\hline \multicolumn{2}{|l|}{ Good work-life balance } \\
\hline Yes & $169(79.0)$ \\
\hline No & $45(21.0)$ \\
\hline
\end{tabular}


Table 1 (continued)

\begin{tabular}{|c|c|}
\hline Characteristic & n (\%) \\
\hline \multicolumn{2}{|l|}{ First job appointment } \\
\hline Yes & $88(41.1)$ \\
\hline No & $126(58.9)$ \\
\hline \multicolumn{2}{|l|}{ Duration before first job appointment } \\
\hline Within 3 months & $150(70.1)$ \\
\hline $3-6$ months & $17(7.9)$ \\
\hline $6-12$ months & $25(11.7)$ \\
\hline$>1$ year & $22(10.3)$ \\
\hline \multicolumn{2}{|l|}{ *Routine task areas } \\
\hline Clinical examination, management, referral & $205(95.8)$ \\
\hline Refraction & $142(98.6)$ \\
\hline Optical dispensing & $211(66.4)$ \\
\hline Contact lens fitting & $63(29.4)$ \\
\hline Low vision care & $51(23.8)$ \\
\hline Community outreaches & $161(75.2)$ \\
\hline Research activities & $49(22.9)$ \\
\hline Diagnostic unit & $80(37.4)$ \\
\hline \multicolumn{2}{|l|}{ *Reason for choosing optometry } \\
\hline Only study opportunity after school & $11(3.0)$ \\
\hline Parental/family influence & $8(2.2)$ \\
\hline Very interest in health and eyecare & $167(45.9)$ \\
\hline Provide voluntary assistance to the needy and NGOs & $48(13.2)$ \\
\hline To earn good income & $69(19.0)$ \\
\hline I believe I can become an eye doctor & $47(12.9)$ \\
\hline Did not know what else to do after school & $8(2.2)$ \\
\hline Other & $6(1.6)$ \\
\hline \multicolumn{2}{|l|}{ Ownership/Partnership with an established private practice } \\
\hline Yes & $55(25.7)$ \\
\hline No & $159(74.3)$ \\
\hline \multicolumn{2}{|l|}{ Opportunity to choose another career when given a choice } \\
\hline Yes & $81(37.9)$ \\
\hline No & $133(62.1)$ \\
\hline
\end{tabular}

$n(\%)$, frequencies and percentages of participants; ${ }^{n} \neq 214$ (multiple responses)

parents/family to choose the optometry career, $2.2 \%$ reported that they did not know what else to do after secondary school, and $1.6 \%$ gave other reasons for choosing optometry at the tertiary level. A few optometrists (25.7\%) had their own/partnered established private practice in Ghana. However, majority of them (62.1\%) were unwilling to choose another career when given the opportunity to start over again (see Table 1).

\section{Level of job satisfaction}

The mean $( \pm \mathrm{SD})$ score for the overall perception of job satisfaction reported by optometrists in Ghana was $3.36 \pm 1.00$, whereas the mean $( \pm \mathrm{SD})$ of the calculated score (an average of the 14 factors associated with job satisfaction) for the overall perception of job satisfaction among optometrists in Ghana was $3.37 \pm 0.73$. Thus, the level of job satisfaction reported by participants was comparable to our calculated overall perception of job satisfaction. Most participants (74.3\%) reported that they were generally satisfied with their current jobs, whereas $25.7 \%$ of respondents were generally not satisfied with their current jobs. Participants were largely satisfied with the level of job responsibility $(3.89 \pm 0.98)$, followed by the level of control over job ( $3.83 \pm 1.07)$, support from co-workers (3.74 \pm 0.94$)$, and job security $(3.63 \pm 1.10)$. On the other hand, participants were largely not satisfied with salary $(2.73 \pm 1.15)$, followed by non-financial incentives $(2.80 \pm 1.11)$, and opportunities for career advancement $(2.89 \pm 1.08)$.

Raw data (Likert scales) of individual job characteristic items were converted to Rasch scores and overall logit scores were calculated for each item. Negative logit scores indicate no satisfaction and positive logit scores indicate satisfaction. The mean logit scores for overall job satisfaction scores was 0.65 logits (scores ranging from - 1.17 to 1.92 logits; see Table 2). Given that the higher the positive logit score, the higher is the satisfaction, overall job satisfaction was high among optometrists in Ghana.

\section{Factors associated with job satisfaction among optometrists in Ghana}

Bivariate simple linear regression analyses (see Table 3) showed that the variables significantly associated $(p<0.05)$ with overall job satisfaction were location of workplace, practice setting, number of working hours, Good work-life balance, Salary, Non-Financial Incentives, Job Security, Workplace Equipment, Supervision, Encouragement, Recognition, Responsibility to Work, Task Variety, Workload Control, Support from Co-Workers, Continuing Education Opportunities, and Career Advancement Opportunities.

On including the variables that were found to be significant in the bivariate regression models, the multiple regression analyses (see Table 3; F $(18,195)=24.89$; $\mathrm{R}$-squared $=0.697, p<0.0005)$ showed that Good worklife balance ( Unstandardized co-efficient $(\beta)=0.288$, $p=0.001)$, Salary $(\beta=0.222, p<0.0005)$, Supervision $(\beta=0.117, p=0.044)$, and Continuing Education Opportunities $(\beta=0.138, p=0.017)$ were all significantly associated with higher levels of overall job satisfaction.

\section{Discussion}

This novel study highlights job satisfaction and its associated factors among optometrists in Ghana. The mean score for the overall perception of job satisfaction reported by optometrists in Ghana was 3.36. Majority of 
Table 2 Rasch Logit Scores for Determinants of Job Satisfaction among Optometrists in Ghana

\begin{tabular}{|c|c|c|c|c|c|}
\hline Job characteristic Items & $\mathbf{N}$ & Minimum & Maximum & Mean & SD \\
\hline Salary & 214 & -0.17 & 2.92 & 1.13 & 0.94 \\
\hline Non-Financial Incentives & 214 & 0.01 & 3.10 & 1.36 & 0.90 \\
\hline Job Security & 214 & -1.15 & 1.94 & 0.89 & 0.89 \\
\hline Workplace Equipment & 214 & -3.42 & -0.33 & -1.64 & 0.93 \\
\hline Supervision & 214 & -0.60 & 2.49 & 1.36 & 0.90 \\
\hline Encouragement & 214 & -0.78 & 2.31 & 0.85 & 0.87 \\
\hline Recognition & 214 & -1.43 & 1.66 & 0.59 & 0.86 \\
\hline Responsibility to Work & 214 & -2.34 & 0.75 & -0.08 & 0.78 \\
\hline Task Variety & 214 & -1.70 & 1.39 & 0.30 & 0.76 \\
\hline Workload & 214 & -0.26 & 2.83 & 1.62 & 0.82 \\
\hline Control & 214 & -2.11 & 0.98 & 0.09 & 0.86 \\
\hline Support from Co-Workers & 214 & -2.13 & 0.96 & 0.01 & 0.76 \\
\hline Continuing Education Opportunities & 214 & -1.45 & 1.64 & 0.12 & 0.95 \\
\hline Career Advancement Opportunities & 214 & -1.57 & 1.52 & -0.16 & 0.88 \\
\hline Overall Job Satisfaction & 214 & -1.17 & 1.92 & 0.65 & 0.83 \\
\hline
\end{tabular}

$\mathrm{N}$, number of participants; SD, Standard Deviation

optometrists $(74.3 \%)$ in Ghana reported that they were largely satisfied with their jobs. The main factors associated with overall job satisfaction were good work-life balance, salary, supervision, and Continuing Education Opportunities.

Job satisfaction levels among healthcare professionals have been studied extensively in many different countries, although limited data exist in Africa. In our study, we found job satisfaction level among optometrists in Ghana to be $74.3 \%$. Our finding was found to be almost similar to the level of job satisfaction among optometrists in the United Kingdom (80\%) [35]. It is however noteworthy that job satisfaction among healthcare professionals has been studied in the Ghanaian population [5, 36-38], although not specifically among optometrists. A cross-sectional study by Bonenberger et al. [5] similarly reported an overall job satisfaction mean score of 3.15 (out of 5) among healthcare professionals in Ghana. The study had a total of 256 healthcare professionals who were systematically sampled from most public health facilities across the Eastern region of Ghana. However, job satisfaction levels were assessed using the Measure of Job satisfaction (MJS) and the Job Descriptive Index (JDI) tools which were validated by Rouleau et al. [39]. Another cross-sectional study by Boafo [37] also reported an overall job satisfaction mean score of 3.19 (out of 5) among nurses in Ghana. However, a total of 592 qualified nurses were recruited in the study, with job satisfaction levels being assessed by the MJS tool only. The use of different instruments (MJS and JDI) to assess the levels of job satisfaction among other healthcare professionals, as opposed to the use of the validated tool by Paudel et al.
[33] which is purposely designed to assess job satisfaction level among eyecare professionals, may have accounted for the slightly higher results obtained among optometrists in our study.

Our study found salary to be significantly associated with overall job satisfaction. This was consistent with a similar survey conducted among the optometric workforce in the United Kingdom [35]. Other studies in Africa have also reported lowest mean score for salary/remuneration in relation to job satisfaction among healthcare professionals [3, 40, 41]. In Ghana, salary/remuneration is perceived to be low among healthcare professionals [17]. Lower financial rewards to these healthcare professionals, including optometrists, may result in low work performance and/or productivity [36], hence the need for stakeholders to adopt policies aimed at enhancing renumeration/salary levels and reducing job turnover among optometrists [42].

The role of supervisory support from organizational leaders has proven to be essential in alleviating health professionals' job turnover and enhancing overall job satisfaction [43]. Healthcare professionals perceive supervisory support as an important indicator for decreasing work-related emotional exhaustion and improving their work performance [44]. Emotional exhaustion or stress is regarded as a risk factor for health professionals' wellbeing and health. In Ghana, a study by Yeboah et al. [45] showed that supervisory support given to health professionals, including optometrists, played a pivotal role in their management of work-related stress. Thus, effective clinical supervision of allied healthcare professionals (e.g. optometrists) ultimately ensures continuous professional 
Table 3 Bivariate and multivariate linear regression analyses of factors associated with overall job satisfaction using rasch logit scores

\begin{tabular}{|c|c|c|c|c|c|c|}
\hline \multirow[t]{3}{*}{ Characteristic } & \multicolumn{6}{|l|}{ Overall job satisfaction } \\
\hline & \multicolumn{3}{|l|}{ Simple regression } & \multicolumn{3}{|l|}{ Multiple regression } \\
\hline & $\begin{array}{l}\text { Unstandardized co-ef } \\
(\beta)\end{array}$ & S.E & $p$ value & $\begin{array}{l}\text { Unstandardized co-ef } \\
\text { ( } \beta)\end{array}$ & S.E & $p$ value \\
\hline Age (years) & 0.007 & 0.009 & 0.449 & & & \\
\hline Sex: male versus female & 0.188 & 0.126 & 0.158 & & & \\
\hline \multicolumn{7}{|l|}{ Marital status } \\
\hline Single & Ref & & & & & \\
\hline Married & 0.023 & 0.117 & 1.000 & & & \\
\hline Divorced & -0.061 & 0.326 & 1.000 & & & \\
\hline Number of children & 0.088 & 0.045 & 0.052 & & & \\
\hline \multicolumn{7}{|l|}{ Location of work place } \\
\hline Urban versus Rural & 0.395 & 0.143 & 0.006 & -0.058 & 0.091 & 0.530 \\
\hline Practice Setting & & & & 0.058 & 0.042 & 0.166 \\
\hline Government & Ref & & & & & \\
\hline CHAG/NGO & -0.369 & 0.158 & 0.204 & & & \\
\hline Private & -0.543 & 0.129 & $p<0.0005$ & & & \\
\hline Academic & -0.859 & 0.259 & 0.011 & & & \\
\hline Others & -0.865 & 0.467 & 0.656 & & & \\
\hline Working hours per week & 0.017 & 0.005 & $p<0.0005$ & 0.002 & 0.003 & 0.422 \\
\hline Work experience (years) & 0.005 & 0.012 & 0.714 & & & \\
\hline \multicolumn{7}{|l|}{ Good work-life balance } \\
\hline Yes versus No & 0.592 & 0.133 & $p<0.0005$ & 0.288 & 0.088 & 0.001 \\
\hline Salary & 0.544 & 0.047 & $p<0.0005$ & 0.222 & 0.049 & $p<0.0005$ \\
\hline Non-Financial Incentives & 0.444 & 0.055 & $p<0.0005$ & 0.080 & 0.047 & 0.091 \\
\hline Job Security & 0.496 & 0.054 & $p<0.0005$ & 0.025 & 0.053 & 0.635 \\
\hline Workplace Equipment & 0.361 & 0.056 & $p<0.0005$ & 0.002 & 0.046 & 0.970 \\
\hline Supervision & 0.550 & 0.051 & $p<0.0005$ & 0.117 & 0.058 & 0.044 \\
\hline Encouragement & 0.505 & 0.056 & $p<0.0005$ & 0.045 & 0.054 & 0.409 \\
\hline Recognition & 0.577 & 0.053 & $p<0.0005$ & 0.099 & 0.063 & 0.118 \\
\hline Responsibility to Work & 0.571 & 0.061 & $p<0.0005$ & 0.041 & 0.075 & 0.583 \\
\hline Task Variety & 0.561 & 0.064 & $p<0.0005$ & -0.057 & 0.073 & 0.434 \\
\hline Workload & 0.493 & 0.060 & $p<0.0005$ & 0.058 & 0.053 & 0.270 \\
\hline Control & 0.622 & 0.051 & $p<0.0005$ & 0.139 & 0.071 & 0.052 \\
\hline Support from Co-Workers & 0.643 & 0.060 & $p<0.0005$ & 0.096 & 0.068 & 0.158 \\
\hline Continuing Education Opportunities & 0.459 & 0.050 & $p<0.0005$ & 0.138 & 0.057 & 0.017 \\
\hline Career Advancement Opportunities & 0.418 & 0.057 & $p<0.0005$ & -0.018 & 0.064 & 0.777 \\
\hline (constant) & & & & -0.472 & 0.251 & 0.062 \\
\hline
\end{tabular}

$F(18,195)=24.89 ;$ R-squared $=0.697, p<0.0005 ;$ S.E., Standard Error of Unstandardized co-efficient $(\beta)$

development and wellbeing, enhance routine clinical tasks, facilitate the delivery of safe and quality eyecare services, and enhance overall job satisfaction [46]. There is therefore the need to develop and implement efficient optometry-specific guidelines and policies on clinical supervision in Ghana, through the leadership of the GOA and AHPC, to support optometrists in their professional role.
The tendency for healthcare professionals to be satisfied at their workplaces may depend on the level of control they have over their work environment. In the United Kingdom, the level of autonomy or independence in job practice was the second most important factor for job satisfaction among optometrists [35]. Lack of control over job, exhibited by some health professionals, signifies a limitation to their sense of discretion 
and autonomy at their workplaces. Working conditions are generally improved when healthcare professionals possess an appreciable level of command over their work environment. Additionally, it has been shown that lack of job control is a precursor to workload and job burnout or stress [47]. In Australia, work-related stress among optometrists was due to factors such as workload and patient-related clinical problems [14]. However, the mitigating effect of job control over workload and work-related stress has been demonstrated in a study by Portoghese et al. [48]. Thus, a good control over an optometrist's job in Ghana may offer him/ her the opportunity to shape his/her work environment (reducing workload and stress), and subsequently hinder turnover intentions, and promote high levels of job satisfaction [49]. Optometrists in Ghana are therefore likely to remain at their workplaces if issues concerning their level of control over job are addressed.

Social desirability bias was minimized in our study through the following means. First, online questionnaires (via Google forms) were self-administered and allowed for privacy. Therefore, responses from our online mail survey cannot be biased by interviewer presence. Anonymity of respondents was assured by storing responses and identification number in different files (thus, not allowing the linking between responses and identifiers). Secondly, trained field staff, who served as Research Assistants, administered face-to-face interviews to respondents in our study. Furthermore, the study employed a psychometrically validated job satisfaction instrument developed by Paudel et al. [33] for use among eyecare professionals only (such as optometrists). This robust instrument improved the quality of psychometric measures in our study, hence minimizing social desirability bias. Moreover, regarding the questionnaire used in our study, closed-ended questions were used where participants had to indicate their responses on a Likert scale. This reduced the tendency to generate social desirability bias.

The strength of this study includes the use of a previously validated questionnaire for data collection among eyecare professionals, which was adapted from Paudel et al. [33]. This instrument provides good precision in measuring the level of job satisfaction among eye care professionals such as optometrists. Secondly, to the best of our knowledge, this survey was the first (novel) study assessing job satisfaction and its associated factors among optometrists in Ghana. However, the crosssectional nature/design of this study makes it difficult to establish a cause-effect relationship between job satisfaction and its associated factors. This serves as a limitation for this study. Practically, the busy schedule of optometrists in their clinical settings, constraints in follow-up, inadequate resources, unstable/poor internet networks (especially in rural communities), and other official engagements by some optometrists made it impossible to achieve a much higher response rate in our study. In Ghana, combined response rates for surveys among optometrists, using both online and printed questionnaires, are $33.5 \%$ [50] and 46\% [51]; which highlights the fact that participants' responses to surveys remains a key challenge, especially among participants from a single profession (i.e. optometrists). Future studies must be conducted to ascertain the association between communication, social relations at the workplace, and work safety, and job satisfaction among optometrists in Ghana.

\section{Conclusions}

On a 1-5-point scale (1-very dissatisfied; 5-very satisfied), the mean score of the overall perception of job satisfaction among optometrists was 3.36 (satisfied). Overall, $74.3 \%$ of optometrist reported that they were satisfied with their jobs. Good work-life balance, salary, supervision, and Continuing Education Opportunities were significantly associated with overall job satisfaction. Findings from this study are very essential to employers, policymakers, healthcare managers, and other stakeholders of the eyecare sector in understanding the impact of job satisfaction on optometrists' retention and productivity at workplaces, as well as policy revision on the national planning and management of human resources for eye health (particularly optometrists) in Ghana and across Africa.

\section{Abbreviations}

WHO: World Health Organization; SDG: Sustainable Development Goals; GOA: Ghana Optometric Association; AHPC: Allied Health Professions Council of Ghana; KNUST: Kwame Nkrumah University of Science and Technology; OR: Odds ratio; Cl: Confidence interval; SD: Standard deviation; OD: Doctor of Optometry; MJS: Measure of Job satisfaction; JDI: Job Descriptive Index.

\section{Acknowledgements}

We would like to acknowledge the leadership and members of the Ghana Optometric Association (GOA) for their support.

\section{Authors' contributions}

ASM and KOA conceived and designed the project. ASM carried out data collection. EAM, AKA and EKA provided technical support. KOA, ASM, EAM, AKA, and EKA performed data analyses. KOA, EAM, DBK, ADA, ASM, AKA, and EKA interpreted data for this study. KOA, EAM, DBK, ADA, ASM, AKA, EKA drafted the work and revised it critically for important intellectual content. KOA supervised the study. All authors read and approved the final manuscript.

\section{Funding}

This research received no specific grant from any funding agency in the public, commercial or not-for-profit sectors.

Availability of data and materials

The dataset used and/or analysed during the current study are available from the corresponding author on reasonable request. 


\section{Ethics approval and consent to participate}

Committee on Human Research Publication and Ethics of the Kwame Nkrumah University of Science and Technology (KNUST) (CHRPE/AP/034/19). Permission was obtained from the Ghana Optometric Association. Written informed consent was obtained from all participants after explaining the objectives, nature, method and importance of the study to them.

\section{Competing interests}

The authors declare that they have no competing interests.

\section{Consent for publication}

\section{Not applicable.}

\begin{abstract}
Author details
${ }^{1}$ Department of Optometry and Visual Science, College of Science, Kwame Nkrumah University of Science and Technology, Kumasi, Ghana. ${ }^{2}$ Usher Institute for Population Health Sciences and Informatics, College of Medicine and Veterinary Medicine, University of Edinburgh, Edinburgh, UK. ${ }^{3}$ Department of Epidemiology and Disease Control, School of Public Health, University of Ghana, Legon, Ghana. ${ }^{4}$ University of Ghana Centre for Evidence Synthesis and Policy, School of Public Health, University of Ghana, Legon, Ghana. ${ }^{5}$ Department of Ophthalmology and Visual Sciences, University of British Columbia, Vancouver, Canada. ${ }^{6}$ Department of Ophthalmology and Visual Sciences, Moran Eye Centre, University of Utah, Salt Lake City, Utah, USA. ${ }^{7}$ Department of Nutrition and Integrative Physiology, University of Utah, Salt Lake City, Utah, USA.
\end{abstract}

\section{Received: 3 June 2020 Accepted: 14 December 2020}

Published online: 07 January 2021

\section{References}

1. Ravari A, Mirzaei T, Kazemi M, Jamalizadeh A. Job satisfaction as a multidimensional concept: a systematic review study. J Occup Health Epidemiol. 2012;1(2):95-102

2. Squires JE, Hoben M, Linklater S, Carleton HL, Graham N, Estabrooks CA. Job satisfaction among care aides in residential long-term care: a systematic review of contributing factors, both individual and organizational. Nurs Res Pract. 2015. https://doi.org/10.1155/2015/157924.

3. Willis-Shattuck M, Bidwell P, Thomas S, Wyness L, Blaauw D, Ditlopo P. Motivation and retention of health workers in developing countries: a systematic review. BMC Health Serv Res. 2008;8(1):247.

4. Nemmaniwar A, Deshpande MS. Job satisfaction among hospita employees: a review of literature. IOSR J Bus Manag. 2016;18(6):27-31.

5. Bonenberger $M$, Aikins $M$, Akweongo P, Wyss K. The effects of health worker motivation and job satisfaction on turnover intention in Ghana: a cross-sectional study. Human Resour Health. 2014;12(1):43.

6. Herzberg FI. Work and the nature of man. Cleveland: World Pub. Co.; 1966.

7. Abraham M. Motivation and personality. Nueva York: Harper \& Row, Publishers; 1954.

8. Judge TA, Larsen RJ. Dispositional affect and job satisfaction: a review and theoretical extension. Organ Behav Hum Decis Process. 2001:86(1):67-98.

9. Hackman JR, Oldham GR. Development of the job diagnostic survey. J Appl Psychol. 1975;60(2):159.

10. Ewen RB. Some determinants of job satisfaction: a study of the generality of Herzberg's theory. J Appl Psychol. 1964:48(3):161.

11. Judge TA, Bono JE. Relationship of core self-evaluations traits — selfesteem, generalized self-efficacy, locus of control, and emotional stability — with job satisfaction and job performance: a meta-analysis. J Appl Psychol. 2001:86(1):80.

12. Zhang M, Yang R, Wang W, Gillespie J, Clarke S, Yan F. Job satisfaction of urban community health workers after the 2009 healthcare reform in China: a systematic review. Int J Qual Health Care. 2016;28(1):14-21.

13. Dilig-Ruiz A, MacDonald I, Varin MD, Vandyk A, Graham ID, Squires JE. Job satisfaction among critical care nurses: a systematic review. Int J Nurs Stud. 2018:88:123-34.

14. Long J, Burgess-Limerick R, Stapleton F. What do clinical optometrists like about their job? Clin Exp Optom. 2013;96(5):460-6.

15. Lu H, Barriball KL, Zhang $X$, While AE. Job satisfaction among hospital nurses revisited: a systematic review. Int J Nurs Stud. 2012;49(8):1017-38.
16. Bhatnagar K, Srivastava K. Job satisfaction in health-care organizations. Ind Psychiatry J. 2012;21(1):75.

17. Alhassan RK, Spieker N, van Ostenberg P, Ogink A, Nketiah-Amponsah E, de Wit TFR. Association between health worker motivation and healthcare quality efforts in Ghana. Hu Resour Health. 2013;11(1):37.

18. Parkins DJ, Curran R, Pooley JE, Ryan B. The developing role of optometrists as part of the NHS primary care team. Optom Pract. 2014;15(4):177-84.

19. De Souza N, Cui Y, Looi S, Paudel P, Shinde L, Kumar K, et al. The role of optometrists in India: an integral part of an eye health team. Indian J Ophthalmol. 2012;60(5):401.

20. Baker H, Ratnarajan G, Harper RA, Edgar DF, Lawrenson JG. Effectiveness of UK optometric enhanced eye care services: a realist review of the literature. Ophthalmic Physiol Opt. 2016;36(5):545-57.

21. Asper $L$, Watt $K$, Khuu S. Optical treatment of amblyopia: a systematic review and meta-analysis. Clin Exp Optom. 2018;101(4):431-42.

22. Boadi-Kusi SB, Ntodie M, Mashige KP, Owusu-Ansah A, Antwi OK. A crosssectional survey of optometrists and optometric practices in Ghana. Clin Exp Optom. 2015;98(5):473-7.

23. Liu L, Swanson M. Improving patient outcomes: role of the primary care optometrist in the early diagnosis and management of age-related macular degeneration. Clin Optom. 2013;5:1-12.

24. Hooper P, Jutai JW, Strong G, Russell-Minda E. Age-related macular degeneration and low-vision rehabilitation: a systematic review. Can J Ophthalmol. 2008;43(2):180-7.

25. Smaakjær P, Tødten ST, Rasmussen RS. Therapist-assisted vision therapy improves outcome for stroke patients with homonymous hemianopia alone or combined with oculomotor dysfunction. Neurol Res. 2018;40(9):752-7.

26. Illahi W, Cardall M. Therapeutic contact lens fitting in a large tertiary referral centre. Contact Lens Anterior Eye. 2018;41(6):471-2.

27. Palmer JJ, Chinanayi F, Gilbert A, Pillay D, Fox S, Jaggernath J, et al. Trends and implications for achieving VISION 2020 human resources for eye health targets in 16 countries of sub-Saharan Africa by the year 2020 . Hum Resour Health. 2014;12(1):45.

28. Palmer JJ, Chinanayi F, Gilbert A, Pillay D, Fox S, Jaggernath J, et al. Mapping human resources for eye health in 21 countries of sub-Saharan Africa: current progress towards VISION 2020. Hum Resour Health. 2014;12(1):44

29. Kiely PM, Slater J. Optometry A ustralia Entry-level Competency Standards for Optometry 2014. Clin Exp Optom. 2015;98(1):65-89.

30. Hashemi H, Fotouhi A, Yekta A, Pakzad R, Ostadimoghaddam H, Khabazkhoob M. Global and regional estimates of prevalence of refractive errors: systematic review and meta-analysis. J Curr Ophthal. 2018;30(1):3-22.

31. Morny EKA, Boadi-Kusi SB, Ocansey S, Kyei S, Yeboah K, Mmaduagwu MA. Assessing the progress towards achieving "VISION 2020: the right to sight" initiative in Ghana. J Environ Public Health. 2019:2019:1-10.

32. Country MRB. World Population Review. URL: http://worldpopulationrevie w.com/countries/murder-rate-by-country. 2020.

33. Paudel P, Cronjé S, O'Connor PM, Khadka J, Rao GN, Holden BA. Development and validation of an instrument to assess job satisfaction in eyecare personnel. Clin Exp Optom. 2017;100(6):683-9.

34. Rayhan RU, Zheng Y, Uddin E, Timbol C, Adewuyi O, Baraniuk JN. Administer and collect medical questionnaires with Google documents: a simple, safe, and free system. Appl Med Inf. 2013;33(3):12.

35. Optometrists Co. The Optical Workforce Survey 2015. 2015.

36. Aduo-Adjei K, Emmanuel O, Forster OM. The impact of motivation on the work performance of health workers (Korle Bu Teaching Hospital): Evidence from Ghana. Hosp Pract Res. 2016;1(2):47-52.

37. Boafo IM. The effects of workplace respect and violence on nurses' job satisfaction in Ghana: a cross-sectional survey. Hum Resources Health. 2018;16(1):6.

38. Tagoe T, Quarshie ENB. The relationship between emotional intelligence and job satisfaction among nurses in Accra. Nurs Open. 2017;4(2):84-9.

39. Rouleau D, Fournier P, Philibert A, Mbengue B, Dumont A. The effects of midwives' job satisfaction on burnout, intention to quit and turnover: a longitudinal study in Senegal. Hum Resour Health. 2012;10(1):9.

40. Hotchkiss DR, Banteyerga H, Tharaney M. Job satisfaction and motivation among public sector health workers: evidence from Ethiopia. Hum Resour Health. 2015;13(1):83. 
41. Delobelle P, Rawlinson JL, Ntuli S, Malatsi I, Decock R, Depoorter AM. Job satisfaction and turnover intent of primary healthcare nurses in rural South Africa: a questionnaire survey. J Adv Nurs. 2011;67(2):371-83.

42. Ramson P, Govender P, Naidoo K. Recruitment and retention strategies for public sector optometrists in KwaZulu-Natal Province, South Africa. Afr Vis Eye Health. 2016;75(1):1-10.

43. Fukui S, Wu W, Salyers MP. Impact of supervisory support on turnover intention: The mediating role of burnout and job satisfaction in a longitudinal study. Admin Policy Mental Health Mental Health Serv Res. 2019;46(4):488-97.

44. Madede T, Sidat M, McAuliffe E, Patricio SR, Uduma O, Galligan M, et al. The impact of a supportive supervision intervention on health workers in Niassa, Mozambique: a cluster-controlled trial. Hum Resour Health. 2017;15(1):58

45. Yeboah MA, Ansong MO, Antwi HA, Yiranbon E, Anyan F, Gyebil F. Determinants of workplace stress among healthcare professionals in Ghana: an empirical analysis. Int J Bus Soc Sci. 2014;5(4):140-51.

46. Snowdon DA, Sargent M, Williams CM, Maloney S, Caspers K, Taylor NF. Effective clinical supervision of allied health professionals: a mixed methods study. BMC Health Serv Res. 2020;20(1):1-11.
47. Maslach C, Leiter M. The truth about burnout Jossey-Bass San Francisco. 1997.

48. Portoghese I, Galletta M, Coppola RC, Finco G, Campagna M. Burnout and workload among health care workers: the moderating role of job control. Saf Health Work. 2014;5(3):152-7.

49. Scanlan JN, Still M. Relationships between burnout, turnover intention, job satisfaction, job demands and job resources for mental health personnel in an Australian mental health service. BMC Health Serv Res. 2019;19(1):62.

50. Asiedu K, Kyei S, Ayobi B, Agyemang FO, Ablordeppey RK. Survey of eye practitioners' preference of diagnostic tests and treatment modalities for dry eye in Ghana. Contact Lens Anterior Eye. 2016;39(6):411-5.

51. Ocansey S, Abu EK, Nii Armah O, Morny EK. The practise of paediatric optometry in a low-resource environment. Clin Exp Optom. 2019;103(4):520-30.

\section{Publisher's Note}

Springer Nature remains neutral with regard to jurisdictional claims in published maps and institutional affiliations.
Ready to submit your research? Choose BMC and benefit from:

- fast, convenient online submission

- thorough peer review by experienced researchers in your field

- rapid publication on acceptance

- support for research data, including large and complex data types

- gold Open Access which fosters wider collaboration and increased citations

- maximum visibility for your research: over $100 \mathrm{M}$ website views per year

At BMC, research is always in progress.

Learn more biomedcentral.com/submissions 